\title{
The Oscar Ramirez Procedure, a Solution for Treating Incisional Hernias with Big Abdominal Wall Defect
}

\author{
Gherghinescu M, Popa D, Panțiru A, Russu C, Roșca C, Benedek Orsolya, Copotoiu C \\ Surgical Clinic 1, County Emergency Clinical Hospital, Tîrgu Mureș, Romania
}

\begin{abstract}
Background: Incisional hernias are important complications of abdominal surgery. Normally they are followed by the growth of the hernia sac and an increase of the abdominal wall defect with loss of domain of the herniated organs.

Case report: We report a case of a 51 year old female, admitted in the $1^{\text {st }}$ Surgical Clinic of the County Emergency Clinical Hospital of Tîrgu Mureș with a large median reducible incisional hernia and a wall defect of 10/12 cm. The abdominoplasty was performed using the Oscar Ramirez technique, which consists of a longitudinal incision along the aponeurosis of the external oblique muscle, at approximately 1-2 cm from the external edge of the rectus abdominis. This procedure allows the abdominal wall closure. This case is part of a lot of 4 patients who received this treatment using the aforementioned procedure in the past 2 months. Postoperative recovery was favorable, bowel movements were present on the second day after the surgery, the subcutaneous drains were shortened on the fifth day and removed on the sixth. There were no immediate postoperative complications or up to a month after the surgery. The patient was discharged on the seventh day.

Conclusions: This technique can be used alone in case of large abdominal wall defects, or prequeling an on-lay mesh procedure addressed to a weak abdominal wall, case in which the functional result is superior to a substitutional mesh.
\end{abstract}

Keywords: Oscar Ramirez procedure, incisional hernia, big abdominal wall defect

Received: 13 July 2013 / Accepted: 25 May 2014

\section{Introduction}

Incisional hernias are important complications of abdominal surgery [1]. Normally they are followed by the growth of the hernia sac and an increase of the abdominal wall defect with the loss of the herniated organs domain. Large incisional hernias, most of the time reoccurring, are frequent among these hernias, thus making the closing of the abdominal wall a challenge for the surgeon. This can be achieved with alloplastic procedures or the use of prosthetic material. Closing the abdominal wall with a mesh demands the use of composite prostheses (silicone based on the visceral side and non-silicone based on the abdominal wall's side) or a polypropylene based mesh if there is a possibility to introduce the big omentum between the mesh and the abdominal organs [1], which is not always the case. The absence of the omentum may cause the intestinal adherence to the mesh with secondary lesions and peritonitis. The technique we advise upon is an alloplastic procedure described in 1990 by Oscar Ramirez et al. [2] which could represent a good alternative for the abdominoplasty.

\section{Case report}

We report a case of a 51 year old female, admitted in the $1^{\text {st }}$ Surgical Clinic of the County Emergency Clinical Hospital of Tîrgu Mureș, with a large median reducible incisional hernia and a wall defect of $10 / 12 \mathrm{~cm}$. This case is part of a lot of 4 patients who received this treatment, using the aforementioned procedure in the past 2 months.
Surgical technique: After thorough skin decontamination, the surgical area is isolated, preferably using self-adhesive foil. The old surgical scar is excised, the hernia sac and its contents is identified and dissected, then the hernia sac is removed followed by adhesiolysis. The abdominal wall plasty was performed using the technique described by Oscar Ramirez [2], which consists of a longitudinal incision along the aponeurosis of the external oblique muscle, at approximately $1-2 \mathrm{~cm}$ from the external edge of the rectus abdominis, thus permitting this to slide to the side of the internal oblique muscle (Figure 1).

Using this procedure the rectus abdominis muscles are closed together on the median line to a distance of 3-5 $\mathrm{cm}$ on both sides of the upper abdomen, $7-10 \mathrm{~cm}$ in the middle abdomen and $1-3 \mathrm{~cm}$ in the lower abdomen, allowing closure of the abdominal wall without any tension. If the wall defect is larger, another $2-4 \mathrm{~cm}$ can be gained by a longitudinal incision on the posterior of the rectus abdominis (Figure 2).

Two drainage tubes are inserted in the abdominal flanks after closing the linea alba, then the incision is closed first by suturing the subcutaneous layer, then the skin. The use of an elastic abdominal binder is advised to prevent the occurrence of seromas and hematomas.

Postoperative evolution was good, bowel activity was present on the second day,the subcutaneous drainage tubes were shortened on the fifth day and completely removed on the sixth. The patient was discharged on the seventh day. Out of the 4 patients, one presented necrosis of the skin on the median line which required necrectomy with secondary suture. In one case, due to the frailty 


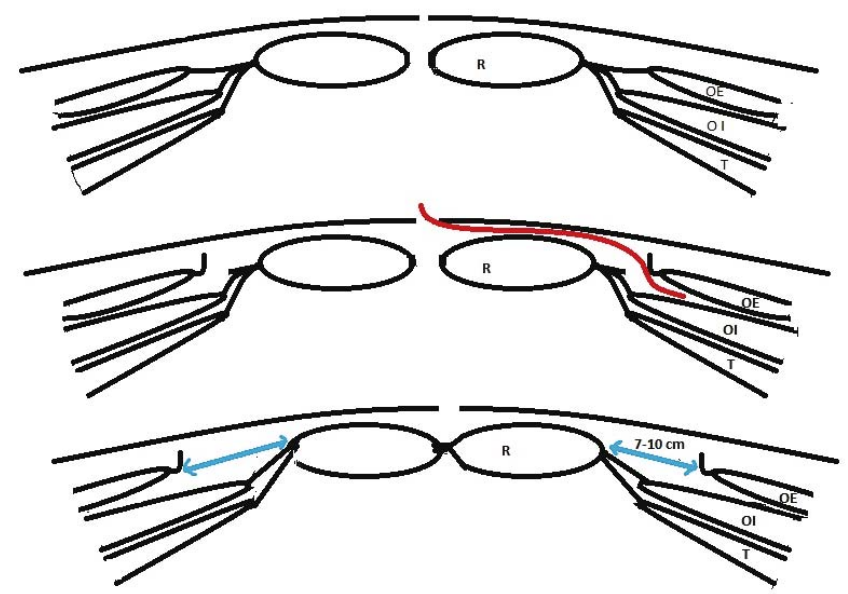

Fig. 1. Oscar Ramirez operative technique

of the abdominal wall, the procedure was reinforced with a polypropylene mesh above the aponeurosis, anchored to the side of the external oblique muscle, with separate non-absorbable sutures for decreasing tension in the suture points.

\section{Discussions}

The described technique, also known as "the components separation technique" is useful for closing large abdominal wall defects if the surgical scar is clean and there is no omentum that can be inserted between a polypropylene mesh and the abdominal organs. It is also useful if the surgical scar is slightly contaminated (granulomas) or highly contaminated (peritonitis or intestinal lesions secondary to a difficult adhesiolysis). Going through the existing literature we have found seven studies based on this procedure, starting with Ramirez in 1990 and ending with Tammo S de Vries Reilingh in 2007 [1] (Table I).

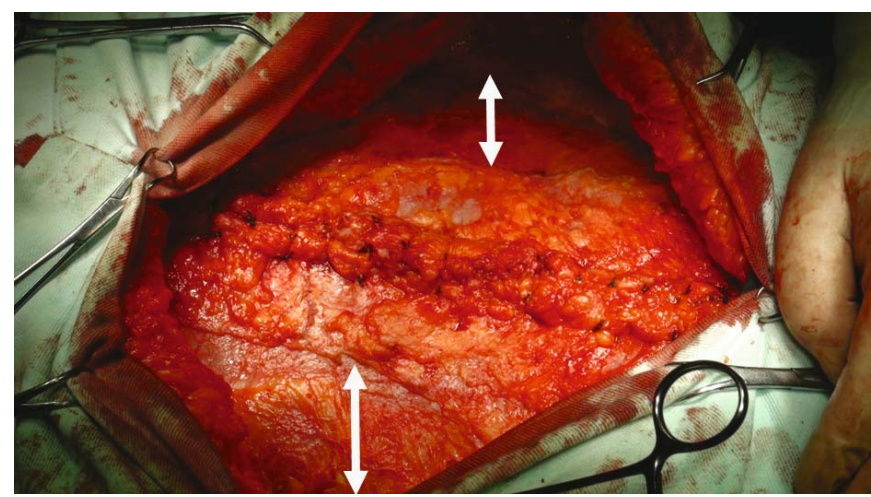

Fig. 2. Intraoperative aspect after Oscar Ramirez procedure

After reviewing these studies we concluded that the most controversial aspect refers to the high rate of reoccurrence $(<30 \%)$ [3], probably due to the fact that most incisional hernias are reoccurring multiple times, accompanied by frailty of the abdominal wall or contaminated surgical scars. Seromas and hematomas may favor infectious complications [10]. Another frequent complication is skin necrosis on the median line (present in our lot of patients too), which can appear due to the large surgical incision that affects the integrity of the perforant vessels coming from the epigastric arteries. This can lead to insufficient blood flow from the intercostal arteries and inferior pudendal artery. Tammo S de Vries Reilingh [4] uses this procedure with endoscopic assistance, by making 2 incisions of $2 \mathrm{cms}$ each and introducing a balloon between the two oblique muscles, inflating the balloon before incising the external oblique muscle's aponeurosis under endoscopic control. By using this technique, which is more esthetic, the vascularizatin is kept and the rate of complications is significantly lower.

Table I. Results of the repair of abdominal wall defects with the component separation technique

\begin{tabular}{|c|c|c|c|c|c|c|}
\hline First author & Year & Patients & $\begin{array}{l}\text { Clean/con- } \\
\text { taminated }\end{array}$ & Complications (n) & Reherniation n (\%) & $\begin{array}{l}\mathrm{n}(\%) \\
\text { Follow-up mean } \\
\text { (range, mo) }\end{array}$ \\
\hline Ramirez [2] & 1990 & 11 & $8 / 3$ & 0 & $0(0.0)$ & $(4-42)$ \\
\hline DiBello [5] & 1996 & 35 & $20 / 15$ & $\begin{array}{l}\text { Wound infection (2) } \\
\text { Hematoma (1) } \\
\text { Seroma (1) }\end{array}$ & $3(8.6)$ & $22(1-43)$ \\
\hline Girotto [6] & 1999 & 33 & $30 / 3$ & $\begin{array}{l}\text { Wound infection (8) } \\
\text { Enterocutaneous fistula (1) }\end{array}$ & $2(6.1)$ & $21(6-57)$ \\
\hline Shestak [7] & 2000 & 22 & & $\begin{array}{l}\text { Wound infection (2) } \\
\text { Seroma (1) } \\
\text { Death (1) }\end{array}$ & $1(5)$ & $52(8-84)$ \\
\hline Lowe [8] & 2000 & 30 & & $\begin{array}{l}\text { Wound infection (12) } \\
\text { Skin ischemia (6) } \\
\text { Skin dehiscence (13) }\end{array}$ & $3(10)$ & 12 \\
\hline Cohen [9] & 2001 & 24 & $15 / 9$ & $\begin{array}{l}\text { Skin dehiscence (2) } \\
\text { Seroma (1) }\end{array}$ & $1(4)$ & $(12-36)$ \\
\hline $\begin{array}{l}\text { Tammo S de Vries } \\
\text { Reilingh [1] }\end{array}$ & 2002 & 43 & $28 / 15$ & $\begin{array}{l}\text { Wound infection (6) } \\
\text { Hematoma (5) } \\
\text { Seroma (2) } \\
\text { Skin necrosis (1) } \\
\text { Fascial dehiscence (1) }\end{array}$ & $12(30)$ & $15.6(12-30)$ \\
\hline
\end{tabular}




\section{Conclusions}

The Oscar Ramirez procedure can be used alone in case of large abdominal wall defect, or prequeling an on-lay mesh procedure adressed to a weak abdominal wall, in which case the functional result is superior to a substitutional mesh.

The use of this procedure is also advised in the absence of the omentum or large contaminated surgical scars, considering the complications of using prosthetic material in these circumstances.

\section{References}

1. De Vries Reilingh TS, van Goor H, Rosman C, et al. Components separation technique for the repair of large abdominal wall hernias. J Am Coll Surg. 2003;196:32-37.

2. Ramirez OM, Ruas E, Lee Dellon A. "Components separation" method for closure of abdominal wall defects: An anatomic and clinical study. Plast Reconstr Surg. 1990;86:519-526.
3. De Vries Reilingh TS, van Goor H, Charbon JA, et al. Repair of large abdominal hernias: Prosthetic bridging versus components separation. A prospective randomized trial. World J Surg. 2007;31(4):756-763.

4. Maas SM, de Vries Reilingh TS, van Goor H, et al. Endoscopically assisted "components separation technique" for the repair of complicated ventral hernias. J Am Coll Surg. 2002;194:388-390.

5. DiBello JN, Moore JH. Sliding myofascial flap of the rectus abdominis muscle for the closure of recurrent ventral hernias. Plast Reconstr Surg. 1996;98:464-469.

6. Girotto JA, Ko MJ, Redett R, et al. Closure of chronic abdominal wall defects: A long-term evaluation of the component separation method. Ann Plast Surg. 1999;42:385-395.

7. Shestak KC, Edington HJD, Johnson RR. The separation of anatomic components technique for the reconstruction of massive midline abdominal wall defects: Anatomy, surgical technique, application and limitations revisited. Plast Reconstr Surg. 2000;105:731-738.

8. Lowe JB, Garza JR, Bowman JL, et al. Endoscopically assisted separation for closure of abdominal wall defects. Plast Reconstr Surg. 2000;105:720-729.

9. Cohen M, Morales R, Fildes J, et al. Staged reconstruction after gunshot wounds to the abdomen. Plast Reconstr Surg. 2001;108:83-92.

10. Bleichrodt R, de Vries Reilingh, et al. Component separation technique to repair large midline hernias. Operative Techniques in General Surgery. 2004;6(3):179-188. 